13. Popov, N. A. 1997. Evolyutsionnye osobennosti porod krasnoy masti po allelyam V-lokusa grupp krovi - Evolutionary features of the red lear species according to alleles of the B-locus of blood grains. Doklady Rossijskoj akademii sel'skohozjajstvennyh nauk - Reports of the Russian Academy of Agricultural Sciences. 5:31-33 (in Russian).

14. Kol'cov, D. N., J. V. Tatueva, V. K. Chernushenko, V. I. Cys', N. S. Petkevich, and V. M. Novikov. 2014. Sovremennoe sostojanie buroj shvickoj porody v Rossijskoj Federacii i perspektivy razvitija - The current state of brown shvitsky breed in the Russian Federation and the prospects of development. "70 let kostromskoj porode krupnogo rogatogo skota". Kostromskaja gosudarstvennaja sel'skohozjajstvennaja akademija - In the collection "70 years to the Kostroma breed of cattle". Kostroma state agricultural academy. Karavayevo. 24-32 (in Russian).

15. Sorokova, P. F., N. A. Popov, and T. I. Osipova. 1988. Geneticheskij analiz skreshhivanija simmental'skogo i krasno-pestrogo golshtinskogo skota po tipam krovi - Genetic analysis of crossing of Simmental and red-motley Holstein cattle according by blood types. "Povyshenie produktivnosti $v$ molochnom i mjasnom skotovodstve", bjulleten' nauchnyh trudov, Vserossijskij institut zhivotnovodstva -"Increasing productivity in dairy and beef cattle", Bulletin of Scientific Works, AllRussian Institute of Animal Husbandry. Dubrovitsy. 92:84-89 (in Russian).

16. Cherkashhenko, V. I. 1984. Geneticheskie osobennosti krupnogo rogatogo skota turano-mongol'skoj gruppy po polimorfnym sistemam krovi v svjazi s sohraneniem genofonda - Genetic features of the cattle of the Turan-Mongolian group on polymorphic blood systems in connection with the preservation of the genofond : dis...kand. biol. nauk - thesis of the PhD. Dr.Sci.Biol. LeningradPushkin. 145 (in Russian).

17. Bailey, D. R. 1981. Caff survival and prewedning grivt in divergent beef dreedsand. J. anim. SC. 52:1244-1245.

18. Bailey, D. R., E. E. Swierstra, and T. Entz. 1988. Postpartum interval in 10 firstgrosses of beef cows inder drylot and range conditions. Canad. J. anim. Sc. 4:1027-1033.

19. Lasley, J. 1979. Further information on the inheritance of horns and sears. Bull-O Vram. 4043.

20. Robertson, A. 1956. Blood Grouping in dairy cattle improvement. Proc. VIIth Intern. Congr. Anim. 2:79-83.

УДК 636.3:575.113/.17

\title{
ГЕНЕТИЧНА ДИФЕРЕНЦАЦІЯ ПОПУЛЯЦІЙ АМУРСЬКОГО САЗАНА ТЗОВ «КАРПАТСЬКИЙ ВОДОГРАЙ» ТА ВАТ «ДОНРИБКОМБІНАТ»
}

\author{
А. Е. МАРІУЦА \\ Інститут рибного господарства НААН (Київ, Україна) \\ mariutsa16@ukr.net \\ Досліджено генетичну структуру амурського сазана за трьома генетико-біохімічними \\ системами крові - трансферин, альбумін, естераза. Встановлений рівень фактичної та \\ очікуваної гетерозиготності, середньої гетерозиготності на локус. \\ Диференціація груп амурського сазана за умовами вирощування $\epsilon$ можливою за \\ розподілом алель них варіантів локусів TF, ALB, EST. \\ Ключові слова: генетична диференціація, амурський сазан, популяція, гетерозиготність, \\ поліморфізм, генетична структура, генетико-біохімічні системи,трансферин, альбумін, \\ естераза
}

Розведення і генетика тварин. 2018. Вип. 55 
GENETIC DIFFERENTIFICATION OF AMUR CARP POPULATIONS IN OJSC "KARPATSKY VODOGRAJ" AND OJSC "DONRIBKOMBINAT"

\section{A. E. Mariutsa}

Institute of Fisheries NAAS (Kyiv, Ukraine)

We investigated genetic structure of the Ukrainian scaled and framed amur carp on six genetic-biochemical systems of blod-TF, ALB, EST. Their level actual and expected heterozygosity per locus has been determined. Defferentiation of amur carp group of different rearing conditions is possible based on the distribution of allele variants of TF, ALB and EST loci.

Keywords: genetic differentiation, the Amur sazan, population, heterozygosity, polymorphism, genetic structure, genetiko-biochemical systems, transferrin, albumin, esterase

\section{ГЕНЕТИЧЕСКАЯ ДИФФЕРЕНЦИАЦИЯ ПОПУЛЯЦИЙ АМУРСКОГО САЗАНА ТЗОВ «КАРПАТСКИЙ ВОДОГРАЙ» И ОАО «ДОНРЫБКОМБИНАТ»}

\section{А. Э. Мариуца}

Институт рыбного хозяйства НААН (Киев, Украина)

Исследована генетическая структура амурского сазана по трем генетикобиохимическим системам крови - трансферрин, альбумин, эстераза. Определен уровень фактической и ожидаемой гетерозиготности, средней гетерозиготности на локус.

Дифференичиаџия групп амурского сазана по условиям разведения является возможной по распределению аллельных вариантов локусов TF, ALB, EST.

Ключевые слова: генетическая дифференциация, амурский сазан, популяция, гетерозиготность, полиморфизм, генетическая структура, генетико-биохимические системы, трансферрин, альбумин, эстераза

Вступ. Амурський сазан належить до східноазіатського підвиду. Поширений у басейні річки Амур, а також в річках та озерах Китаю. Йому притаманні підвищена швидкість росту, зимостійкість, виживання, стійкість до краснухи коропа та запалення плавального міхура. Високі пошукові здібності, особливо у поїданні бентосу, що дає можливість підвищити продуктивність вирощувальних ставів на 25\% і нагульних - до $15 \%$. Плідники амурського сазана були завезені восени 1937 р. 3 Далекого Сходу в рибне господарство «Спартак» Курганської області.

На Україну амурський сазан вперше був завезений в 1954 p. із оз. Нароч в Шацький рибозавод Волинської області [1].

У 1939 р. розпочали промислову гібридизацію амурського сазана 3 галіційським коропом 3 розкиданою лускою. Промислова гібридизація коропа 3 амурським сазаном $\epsilon$ одним з методів підвищення ефективності ставового рибництва. Перехід на гібридну форму розведення коропа 3 амурським сазаном дозволяє забезпечити в окремих господарствах стабільно високі показники як по виходу молоді з зимівлі, так і отримання товарної риби в період іiі нагулу. Завдяки підвищенню зимостійкості і наднормативного виходу гібридів 3 зимівлі господарства не тільки повністю забезпечують свої потреби в посадковому матеріалі, а й реалізують його надлишки іншим організаціям, що є економічно вигідним. Доцільність подальшого використання в промисловій гібридизації амурського сазана є обгрунтованою, насамперед у зв'язку із створенням коропово-сазанових гібридів для трьохлітнього циклу ведення ставового господарства в різних зонах рибництва [2].

Однак, для оцінки генетичної структури популяції, напрямку іiі динаміки, генетикобіохімічні маркери мають ряд переваг, зокрема: консерватизм алельних варіантів білків, знання їх біохімічних функцій та причин їх поліморфізму (амінокислотні заміни, що спричиняють зміну електрофоретичної рухливості). Оскільки відомі біохімічні функції досліджуваної генетико-біохімічної системи то порівняльний аналіз їх змін дає можливість робити висновки про те, які саме ланки загального метаболізму залучаються під час генетичної диференціації популяцій, зокрема сазана, в процесі його адаптації до умов навколишнього середовища при інтродукції на території України. 
Виявлення і аналіз поліморфних білкових систем риб є важливим для вирішення багатьох теоретичних і практичних проблем, пов'язаних з раціональною організацією рибного господарства і селекцією риб. Характеристика генетичної структури породних груп риб з використанням методів біохімічної генетики дозволяє оцінювати особливості їх походження, визначати ступінь їх генетичної подібності, а також вивчення специфічних особливостей динаміки генофондів у відповідь на дію факторів штучного і природного відборів [3, 13].

3 метою вивчення генетичних особливостей будови генетичної структури амурського сазана проведено аналіз розподілу алелів і генотипів за електрофоретичними варіантами окремих генетико-біохімічних систем.

Матеріали і методи. Виконано порівняльний аналізгенетичної структури двох груп риб: амурського сазана ТзОВ «Карпатський водограй» $(\mathrm{n}=30)$ і ВАТ «Донрибкомбінат» $(\mathrm{n}=30)$. Матеріалом для аналізу була плазма крові, яку отримали шляхом фракціонування крові, відібраної з хвостової вени. В якості консерванту використовували гепарин. Відібрану кров фракціонували центрифугуванням протягом 15 хвилин за 3,5 тис. об/хв. Отримані фракції плазми крові, лейкоцитів та еритроцитів фасували в одноразові конічні пластикові пробірки об'ємом 1,5 мл, заморожували і зберігали за температури $\left(-18^{0} \mathrm{C}\right)$. Методом електрофорезу в поліакриламідному 9\% гелі і наступним специфічним для кожної генетико-біохімічної системи фарбуванням, виявляли поліморфізм локусів трансферину (Tf), естерази (Est) та альбуміну (Alb) плазми крові $[4,5]$.

Математичну обробку отриманих даних виконували за допомогою комп'ютерної програми „BIOSYS“ [6]. Відхилення фактичних частот від теоретично очікуваних за формулою Гарді-Вайнберга, здійснювали з використанням критерію Пірсона [7]. Критичне значення $\chi^{2}$ брали для 5\% рівня значущості. Для аналізу популяційно-генетичної структури використовували F-статистику Райта [8].

Результати дослідження. Трансферин є транспортним білком плазми крові, який транспортує іони заліза, необхідні для синтезу молекул гемоглобіну. Локус $\mathrm{Tf}$ характеризується високою мінливістю у риб різних видів, число алелів у ньому варіює від 2 до 15 [3]. Поліморфізм трансферину має спадковий характер. Успадкування Tf кодомінантне, Tf в геномі представлений, переважно, одним локусом [9]. Результати власного дослідження виявили п'ять алельних форм за локусом трансферину: $\mathrm{f}^{\mathrm{A}}, \mathrm{Tf}^{\mathrm{B}}, \mathrm{Tf}^{\mathrm{C} 1}, \mathrm{Tf}^{\mathrm{C} 2}, \mathrm{Tf}^{\mathrm{D}}$. Найбільш поширеними генотипамиє ті, які складаються з алелів $\mathrm{Tf}^{\mathrm{C}}{ }_{1}$, $\mathrm{Tf}^{\mathrm{C} 2}$. Порівняння фактичних і теоретично розрахованих частот генотипів виявило наявність незначного надлишку гетерозигот у досліджених популяціях.

У плідників плем’ядра ВАТ «Донрибкомбінат» (в подальшому популяція № 1) частота алеля $\mathrm{Tf}^{\mathrm{C1}}$ була найвищою і становила 0,400 , тоді як у плідників плем'ядра ТзОВ «Карпатський водограй» (в подальшому популяція № 2) частота алеля $\mathrm{Tf}^{\mathrm{A}}$ також була зафіксована на досить високому рівні і становила 0,417 (табл. 1). 3 найменшою частотою зустрічався алель $\mathrm{Tf}^{\mathrm{B}} 0,050$. Деякі дослідники відмічають наявність у далекосхідного амурського сазана підвищеної концентрації $\mathrm{Tf}^{\mathrm{D}}(\mathrm{p}=0,640)$, тоді як для європейських популяцій сазана характерна його невисока частота $[11,12]$. В досліджуваних нами популяціях, насиченість алелем $\mathrm{Tf}^{\mathrm{D}}$ становила в популяції № $1 \mathrm{p}=0,100$, а у ВАТ «Карпатський водограй» спостерігали подібну його частоту $\mathrm{p}=0,150$.

Аналіз генотипів $\mathrm{Tf}$ ( за п’ятьма алелями в сазанів у популяції № 1 і № 2) показав, що із 15-ти можливих комбінацій наявні лише 12, серед яких у плідників популяції № 1 домінував генотип $\mathrm{C}_{1} \mathrm{C}_{1}(\mathrm{p}=9)$, а в популяції № 2 - генотип $\mathrm{AC}_{1}(\mathrm{p}=8)$. В популяції № 1 на відміну від іншої, були відсутні генотипи АA і ВС1, а в популяції № 2 були відсутніми генотипи $\mathrm{BB}, \mathrm{BC}_{2}$, $\mathrm{B}_{1} \mathrm{D}$. Аналіз відповідності фактичного розподілу генотипів трансферінового локусу у досліджених вибірках по відношенню до теоретично очікуваного за Гарді - Вайнбергом виявив, що фактична гетерозиготність в популяції № $1\left(\mathrm{H}_{\mathrm{o}}=0,5\right)$ була нижчою, тоді як у популяції № 2 $\left(\mathrm{H}_{\mathrm{o}}=0,9\right)$, навпаки, вищою від розрахованого значення. 
1. Частоти алелів поліморфних локусів популяцій амурського сазана (Сурrinus carpiohaematopterus)

\begin{tabular}{|c|c|c|c|c|}
\hline Локус & \multicolumn{2}{|c|}{ ВАТ «Донрибкомбінат» } & \multicolumn{2}{c|}{ ТзОВ «Карпатський Водограй» } \\
\hline & алелі & частоти & алелі & частоти \\
\hline TF & $\mathrm{A}$ & 0.333 & $\mathrm{~A}$ & 0.417 \\
\hline & $\mathrm{B}$ & 0.100 & $\mathrm{~B}$ & 0.050 \\
\hline & $\mathrm{C}_{1}$ & 0.400 & $\mathrm{C}_{1}$ & 0.250 \\
\hline & $\mathrm{C}_{2}$ & 0.367 & $\mathrm{C}_{2}$ & 0.133 \\
\hline $\mathrm{DST}$ & $\mathrm{D}$ & 0.100 & $\mathrm{D}$ & 0.150 \\
\hline & $\mathrm{F}$ & 0.267 & $\mathrm{~F}$ & 0.450 \\
\hline $\mathrm{ALB}$ & $\mathrm{S}$ & 0.733 & $\mathrm{~S}$ & 0.550 \\
\hline & $\mathrm{A}$ & 0.350 & $\mathrm{~A}$ & 0.550 \\
\hline
\end{tabular}

Естераза (Est) є ферментом плазми крові, який каталізує синтез та гідроліз складних ефірів. Естерази належать до класу гідролаз та беруть участь в реакціях розщеплення.

На результати популяційно-генетичних досліджень риб мають суттєвий вплив екологічні умови в яких вони мешкають, що призводить до суттєвих змін частот їх генотипів за локусами естераз. Локус Est-1 - поліморфний і представлений трьома генотипами - FF, FS i SS. Виявлено дві форми естерази, що відрізняються швидкістю руху в електричному полі: F швидка i $\mathrm{S}$ - повільна. За локусом естерази в обох популяціях амурського сазана переважала частота Est ${ }^{\text {S: }}$ що в популяції № 1 склала 0,733 і 0,550 в іншій. Із трьох теоретично можливих генотипів естерази в популяції № 1 був відсутній генотип FF. Для обох популяцій був характерним неврівноважений стан, оскільки нами встановлений статистично значущий надлишок гетерозигот в обох досліджених популяціях (16 і відповідно в іншій 17) порівняно із теоретично розрахованим за формулою Гарді -Вайнберга.

Альбумін (Alb) - основний білок плазми крові, що складає 40-60\% від загальної кількості білка плазми. За локусом альбуміну в сазана, як і в переважній більшості інших видів риб, виявлено два алеля А і В. Як і у випадку естерази, за даним локусом спостерігався надлишок гетерозигот (AB). Серед досліджуваних популяцій рівень середньої гетерозиготності був підвищеним у популяції № 1 (0,590), що свідчить про високий розмах генетичної мінливості і потребує застосування селекційних заходів 3 підвищення генетичної консолідації стада.

Аналіз відповідності фактичного розподілу генотипів теоретичному значенню за ГардіВайнбергом показав генетично збалансований стан локусів Est i Alb (табл. 2).

Слід відмітити, що в малих популяціях можуть проявлятись негативні наслідки генетичного дрейфу, які супроводжуються фіксацією рецесивних алелів і зниженням загальногорівня мінливості.

2. Співвідноення фактичної частоти генотипів до очікуваної, здідно закону ГардіВайнберга в популяціях амурського сазана (Cурrinus carpiohaematopterus)

\begin{tabular}{|c|c|c|c|c|c|c|}
\hline \multirow{3}{*}{ Локус } & \multicolumn{4}{|c|}{ Популяція } & \multirow{2}{*}{\multicolumn{2}{|c|}{$\begin{array}{c}\text { Загалом за двома популяці- } \\
\text { ями }\end{array}$}} \\
\hline & \multicolumn{2}{|c|}{ ВАТ «Донрибкомбінат» } & \multicolumn{2}{|c|}{ ВАТ «Карпатський водограй» } & & \\
\hline & d.f. & $\chi_{2}$ & d.f. & $\chi_{2}$ & d.f. & $\chi_{2}$ \\
\hline $\mathrm{TF}$ & 9 & $21,50 *$ & 10 & $21,60 *$ & 19 & 43,10 \\
\hline EST & 2 & 3,58 & 2 & 4,10 & 4 & 7,7 \\
\hline ALB & 2 & 4,34 & 2 & 4,74 & 4 & 9,1 \\
\hline
\end{tabular}

Примітка: d.f. - число ступенів вільності; * - фактичне значення критерія Пірсона вище табличного при рівні значущчості 5\%.

На основі розрахунку коефіцієнтів інбридингу Райта [8] встановлено, що на міжпопуляційну мінливість у амурського сазана припадає 36,9\% від виявленої генетичної мінливості (табл. 3). 
3. Аналіз генетичної різноманітності популяцій амурського сазана (Сурrinus carpiohaетаtopterus) за трьома гетерозиготними локусами

\begin{tabular}{|c|c|c|c|c|c|c|}
\hline Локус & $\mathrm{H}_{\mathrm{o}}$ & $\mathrm{H}_{\mathrm{S}}$ & $\mathrm{H}_{\mathrm{T}}$ & $\mathrm{F}_{\mathrm{IT}}$ & $\mathrm{F}_{\mathrm{IS}}$ & $\mathrm{F}_{\mathrm{ST}}$ \\
\hline $\mathrm{TF}$ & 0,630 & 0,700 & 0,967 & 0,100 & 0,320 & 0,276 \\
\hline EST & 0,641 & 0,445 & 0,750 & $-0,44$ & 0,145 & 0,410 \\
\hline АLB & 0,415 & 0,435 & 0,750 & 0,045 & 0,447 & 0,420 \\
\hline В середньому & 0,562 & 0,527 & 0,822 & $-0,098$ & 0,304 & 0,369 \\
\hline
\end{tabular}

Примітка: $\mathrm{H}_{\mathrm{o}}$ - середня фактична гетерозиготність вибірок; $\mathrm{H}_{\mathrm{s}}-$ середня очікувана гетерозиготність вибірок; $\mathrm{H}_{\mathrm{T}}$ - загальне генетичне різноманіття; $\mathrm{F}_{\mathrm{IT}}$ - коефіцієнт інбридингу особини відносно вибірки; $\mathrm{F}_{\mathrm{IS}}-$ коефіцієнт інбридингу особини відносно видув цілому; F цілому.

Між досліджуваними популяціями амурського сазана рівень генетичної диференціації був найвищим за локусом трансферину при загальному генетичному різноманітті 0,967 . Цього потрібно було очікувати, виходячи із суттєвої різниці частот алелів між популяціями. Через значне відхилення значень частот алелів досліджуваних локусів від теоретично очікуваного розподілу за законом Гарді - Вайнберга, середнє значення коефіцієнту інбридингу особин відносно виду в цілому становило $\mathrm{F}_{\mathrm{IS}}=0,304$. Від'ємне середнє значення $\mathrm{F}_{\mathrm{IT}}$, яке становить 0,098, пояснюється надлишком фактичних гетерозигот в обох популяціях за локусом естерази.

Зростання частоти одних алелів і зниження частоти інших в популяції, на думку деяких авторів, можливе при проведенні штучного відбору за будь-якими рибогосподарськими ознаками і залежить від умов утримання риб [10].

Висновки. В результаті порівняльного аналізу генетичної структури амурського сазана ТзОВ «Карпатський водограй» і ВАТ «Донрибкомбінат» за розподілом алель них варіантів генетико- біохімічних систем - TF, ALB, EST, встановлено, що для диференціації за умовами вирощування амурського сазана доцільно використовувати локуси TF, ALB, EST. Популяції амурського сазана характеризуються високим рівнем міжпопуляційної генетичної диференціації, особливо у відношенні локусу трансферину. Одержані результати дозволяють припускати, що оцінка генетичного поліморфізму риб в аквакультурі саме за обраними для дослідження системами може сприяти об'єктивному контролю ступеню інбридингу груп, а також змін їх генетичної структури в ряду поколінь і за різних умов розведення.

Від'ємне середнє значення FIS засвідчує значне відхилення фактичних частот генотипів від теоретично очікуваних за Гарді - Вайнбергом і $є$ свідченням надлишку гетерозигот у риб досліджених популяцій. Отже, виходячи із значень середньої гетерозиготності, досліджувані вибірки племінного ядра провідних племінних підприємств з розведення амурського сазана характеризуються високим розмахом генетичної мінливості і потребують в подальшому генетичної консолідації.

\section{БІБЛІОГРАФІЯ}

1. Томіленко, В. Г. Розведення коропа / В. Г. Томіленко, С. М. Панченко, Ю. О. Желтов. Київ : Урожай. - 1978. - 104 с.

2. Богерук, А. К. Каталог пород карпа (Cyprinus carpio L) стран Центральной и Восточной Европы / А. К. Богерук ; Министерство сельського хозяйства Российской Федерации. Федеральный селекционно - генетический центр рыбоводства. - Москва. - 2008. - 192 с.

3. Паавер, Т. Биохимическая генетика карпа (Cyprinuscarpio L.) / Т. Паавер. - Таллин : Валгус, 1983. - 122 с.

4. Корочкин, Л. И. Генетика изоферментов / Л. И. Корочкин, О. Л. Серов, А. И. Пудовкин, А. А. Аронштам, Л. Я. Боркин, С. И. Малецкий, Е. В. Полякова, Г. П. Манченко. - М. : Наука, 1997. -275 c.

5. Gahne B. Horizontal polyacrylamide gradientgelelectrophoresis for the simultaneous phenotyping of transferring, post-transferrin, albumin and postalbuminin the blood plasna of cattle / B. Gahne, R. K. Juneja, J. Grolmus. - Anim. Blood Groups Biochem. Genet. - 1997. - V. 8. - P. 127-137.

6. Swofford, D. L. BIOSYS-1: a Fortran program for the comprehensive analysis of electrophoretic data in population genetics and systematic / D. L. Swofford, R. B. Selander // J. Heredity. 1981. - V. 2. - P. 281-283. 
7. Животовський, Л. А.Популяционная биометрия / Л. А. Животовський. - М. : Наука, 1991. $-271 \mathrm{c}$.

8. Wright S. The genetical structure of population / S. Wright. - Ann.Eugen. - 1951. -V. 15. P. 323-354.

9. Тарасюк С. І. Молекулярно-генетичні дослідження в рибництві / С. I. Тарасюк, I. I. Грициняк. - Київ : Аграрна Наука. - 2013. - 310 с.

10. Сапрыкин, В. Г. Корреляция трансферринов с ростом карпов в различных условиях среды / В. Г. Сапрыкин // Сборник аучных трудов ГосНИОРХ. - 1980. - Вып. 153. - С. 100104.

11. Балахнин, И. А. Типы транферрина Cyprinuscarpio L. / И. А. Балахнин, Н. П. Галаган // Гидробиол. журн. - 1972. - Т. 8, № 6. - С. 108-110.

12. Holmes, R. S. Developmental Genetics of the Esterase Isozymes of Fundulusheteroclitus / R. Holmes, G. Whitt. - Biochemical Genetics, 1970. - V. 4. - P. 471-486.

13. Фермерське рибництво / І. І. Грициняк, М. В. Гринжевський, О. М. Третяк, М. С. Ківа, А. І. Мрук. - К. : Рибка моя, 2008. - 696 с.

\section{REFERENCES}

1. Tomilenko, V. G., S. M. Panchenko, and Yu. O. Zheltov. 1978. Rozvedennia koropa - Breeding carp. - Kiev, Urozhai. 102 (in Ukrainian).

2. Bogeruk, A. K. 2008. Katalog porod karpa (Cyprinus carpio L) stran Central'noj i Vostochnoj Evropy - The catalog of carp breeds (Cyprinus carpio L) of countries of Central and Eastern Europe. Ministerstvo sel's'kogo hozjajstva Rossijskoj Federacii. Federal'nyj selekcionno - geneticheskij centr rybovodstva - Ministry of Agriculture of the Russian Federation. Federal selection and genetic center of fish farming. Moscow. 192 (in Russian).

3. Paaver, T. 1983. Biohimicheskaya genetika karpa (Cyprinussarpio L.)-Biochemical genetic of carp (Cyprinussarpio L.). Tallin, Valgus. 122 (in Russian).

4. Korochkin, L. I., O. L. Serov, A. I. Pudovkin, A. A. Aronshtam, L. Ya. Borkin, C. I. Maletskii, E. V. Polyakova, and G. P. Manchenko. 1997. Genetika izofermentov - Genetics of isoenzymes. M., Nauka. 275 (in Russian).

5. Gahne, B., R. K. Juneja, and J. Grolmus. 1997. Horizontal polyakrylamide gradient gel electrophoresis fort hesimultaneous phenotyping of transferring, post-transferrin, albumin and postalbuminin the blood plasna of cattle. Anim. Blood Groups Biochem. Genet. 8:127-137 (in English).

6. Swofford, D. L, and R. B. Selander. 1981. BIOSYS-1: a Fortran program for the comprehensive analysis of electrophoretic data in population genetics and systematic. J. Heredity. 72:281-283 (in English).

7. Zhivotovsky, L. A. 1991. Populyacionnaya biometriya - Population biometrics. M., Nauka. 271 (in Russian).

8. Wright, S. 1951. The genetical structure of population. Ann. Eugen. 15:323-354 (in English).

9. Tarasyuk, S. I., and I. I. Gritsyak. 2013. Molekuliarno-henetychni doslidzhennia v rybnytstvi Molecular genetic studies in fish culture. Kyiv, Ahrarna Nauka. 310 (in Ukrainian).

10. Saprykin, V. G. 1980. Korrelyaciya transferrinov s rostom karpov v razlichnyh usloviyah sredy - Correlation of transferrin with carp growthunder differenten vironmental conditions. Sbornik nauchnyh trudov Gos NIORH - State Scientific Research SRILRF, 153:100-104 (in Russian).

11. Balahnin, I. A., and N. P. Galagan. 1972. Tipy tranferrina Cyprinus carpio L. - Types of transferrin Cyprinus carpio L. Hydrobiological Journal. 8(6):108-110 (in Russian).

12. Holmes, R. S., andG. Whitt 1970. Developmental Genetics of the Esterase Isozymes of. Fundulusheteroclitus. Biochemical Genetics, 4:471-480 (in English).

13. Gritsinyak, I. I., M. V. Grinzhevs'kiy, O. M. Tretyak, M. S. Kiva, and A. I. Mruk. 2008. Fermers'ke ribnitstvo - Fishfarming. - Kyiv : Ribka moya, 696 (in Ukrainian). 